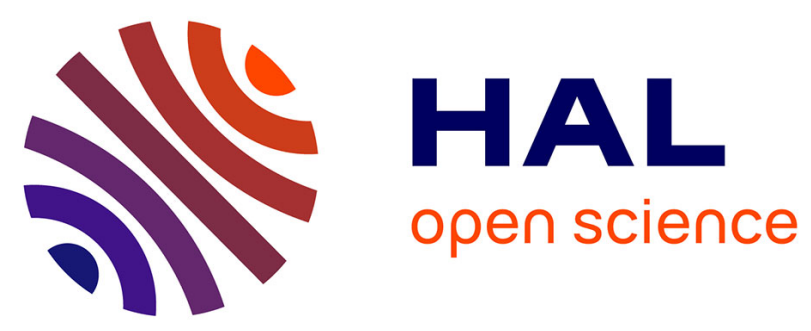

\title{
Recyclable synthesis of Cs-ABW zeolite nanocrystals from non-reacted mother liquors with excellent catalytic henry reaction performance
}

Tamara Mahmoud Ali Ghrear, Eng-Poh Ng, Cyril Vaulot, T. Jean Daou, Tau

Chuan Ling, Soon Huat Tan, Boon Seng Ooi, Svetlana Mintova

\section{To cite this version:}

Tamara Mahmoud Ali Ghrear, Eng-Poh Ng, Cyril Vaulot, T. Jean Daou, Tau Chuan Ling, et al.. Recyclable synthesis of Cs-ABW zeolite nanocrystals from non-reacted mother liquors with excellent catalytic henry reaction performance. Journal of Environmental Chemical Engineering, 2020, 8 (1), pp.103579. 10.1016/j.jece.2019.103579 . hal-02893867

\section{HAL Id: hal-02893867 https://hal.science/hal-02893867}

Submitted on 26 Nov 2020

HAL is a multi-disciplinary open access archive for the deposit and dissemination of scientific research documents, whether they are published or not. The documents may come from teaching and research institutions in France or abroad, or from public or private research centers.
L'archive ouverte pluridisciplinaire HAL, est destinée au dépôt et à la diffusion de documents scientifiques de niveau recherche, publiés ou non, émanant des établissements d'enseignement et de recherche français ou étrangers, des laboratoires publics ou privés. 


\title{
Recyclable Synthesis of Cs-ABW Zeolite Nanocrystals from Non-reacted
} Mother Liquors with Excellent Catalytic Henry Reaction Performance

\author{
Tamara Mahmoud Ali Ghrear, ${ }^{1}$ Eng-Poh Ng, ${ }^{1,}$ Cyril Vaulot, ${ }^{2,3}$ T. Jean Daou, ${ }^{2,3}$ Tau Chuan \\ Ling, ${ }^{4}$ Soon Huat Tan, ${ }^{5}$ Boon Seng Ooi,${ }^{5}$ Svetlana Mintova ${ }^{6}$ \\ ${ }^{1}$ School of Chemical Sciences, Universiti Sains Malaysia, 11800 USM, Penang, Malaysia. \\ ${ }^{2}$ Université de Haute-Alsace, Axe Matériaux à Porosités Contrôlées, Institut de Science de \\ Matériaux de Mulhouse UMR 7361, ENSCMu, 3 b rue Alfred Werner, 68093 Mulhouse, France. \\ ${ }^{3}$ Université de Strasbourg, 67000 Strasbourg, France. \\ ${ }^{4}$ Institute of Biological Sciences, Faculty of Science, University of Malaya, 50603 Kuala Lumpur, \\ Malaysia. \\ ${ }^{5}$ School of Chemical Engineering, Engineering Campus, Universiti Sains Malaysia, Penang, \\ Malaysia. \\ ${ }^{6}$ Normandie Université , ENSICAEN, UNICAEN, CNRS, LCS, 14000 Caen France. \\ *Corresponding author. E-mail address: epng@usm.my
}

\begin{abstract}
Nanoscale zeolites are very attractive for advanced applications such as in catalysis, adsorption, supports, sensors and carriers. Green synthesis of these materials is highly appreciated aiming to increase product yield while chemical waste and production cost can be reduced. Here we report high-yield, low-cost and green synthesis of nanosized Cs-ABW zeolite by recycling and using the non-reacted mother liquors waste solutions produced from the hydrothermal Cs-ABW zeolite synthesis. The nanocrystalline Cs-ABW solid product of each successive batch was collected and characterized while the non-reacted mother liquors were recovered and re-used for subsequent synthesis of nanozeolites. The synthesized Cs-ABW zeolite nanocrystals from three subsequent
\end{abstract}


cycles possessed fairly similar properties and they exhibited excellent catalytic performance in Henry (nitroaldol) reaction of benzaldehyde and nitroethane thanks to their basic sites, $(\mathrm{Si}-\mathrm{O}-\mathrm{Al})^{-}$ $\mathrm{Cs}^{+}$, located at the external surface of the zeolite. This approach hence suggests a low-cost and eco-friendly preparation of Cs-ABW zeolite nanocrystals since less chemical waste is disposed while the product yield can be significantly improved which are ideal for industrial scale-up process.

Keywords: Zeolite; Cs-ABW; Recyaclable synthesis; Nanocatalyst; Henry reaction

\section{Introduction}

Zeolites are hydrated aluminosilicate microporous materials that are widely used in catalysis, adsorption, and ion exchange [1-3]. Recently, zeolites in nanometer scale receive enormous scientific and commercial attentions due to their unique size- and shape-dependent properties (e.g. external surface area, diffusivity, colloid stability, electronic, etc.) [4-9]. While more than 250 types of zeolite known today, only 20 types of zeolite (ABW [10], AEI [11], AFI [12], AFO [13], ANA [14], *BEA [15], CHA [16], EDI [17], EMT [18], FAU [19, 20], GIS [21], LTA [22], LTJ [23], LTL [24], MEL [25], MER [26], MFI [27, 28], MOR [29], SOD [30]) have been successfully synthesized in nanometer scale.

Several efforts have been initiated to synthesize zeolites cost-effectively by optimizing the product yield while minimizing the generation of chemical wastes [31-33]. For instance, Lee et al. reported a method where the organic template can be dissociated, recombined and reused after the zeolite synthesis [31]. Since then, the synthesis of aluminophosphate zeotype materials by 
reusing mother liquor wastes with minimal compensation is investigated $[32,33]$. Nevertheless, the development of eco-friendly and cost-effective synthesis route of industrially important zeolite catalysts still remains a challenge.

ABW-type zeolite is a small pore (8-membered ring) zeolite with an opening of $3.4 \times 3.8$ $\AA^{2}$ [34]. Particularly, nanosized ABW zeolite containing $\mathrm{Cs}^{+}$extraframework cation is of great interest due to its high basicity property that is demanded in heterogeneous catalysis. In addition, its small porosity is also ideal for the separation of small molecules in membrane technology besides being used as a host for immobilization of radioactive cesium [35]. Recently, nanosized Cs-ABW zeolite has been successfully synthesized free of organic template under relatively low pressure and temperature $\left(180{ }^{\circ} \mathrm{C}, 22\right.$ bar) [10] as compared to the previous works $\left(700-1200{ }^{\circ} \mathrm{C}\right.$, $>1000$ bar) [36]. As like other nanozeolites, the use of excessive structure-directing agent $(\mathrm{CsOH}$ in this case) for obtaining nanosized Cs-ABW with moderate crystalline solid yield is essential as it promotes supersaturation condition for allowing nucleation over crystal growth to take place. The desired solid products after the hyrothermal synthesis are then separated while the mother liquors that often contain non-reacted reagents are usually discarded as waste. This makes CsABW nanozeolite synthesis not economical and environment-unfriendly due to the disposal of large amount of expensive, corrosive and harmful non-reacted chemicals, particularly $\mathrm{CsOH}$.

To make use of the surplus chemicals effectively and further enhance the product yield of Cs-ABW nanozeolite, in this paper, a simple and eco-friendly method by recycling the non-reacted mother liquors to prepare $\mathrm{Cs}-\mathrm{ABW}$ nanozeolite is reported. More importantly, the resulting nanosized Cs-ABW zeolites from three subsequent cycles of synthesis exhibit almost similar properties and they show excellent catalytic performance in Henry (nitroaldol) reaction. 


\section{Experimental}

\subsection{Recyclable synthesis of Cs-ABW zeolite nanocrystals}

All the chemicals were purchased from commercial sources and used without further purification. First, clear aluminate solution was prepared by dissolving $\mathrm{CsOH} \cdot \mathrm{H}_{2} \mathrm{O}(28.000 \mathrm{~g}$, $\geq 99.5 \%$, Sigma-Aldrich) and $\mathrm{Al}(\mathrm{OH})_{3}(3.312 \mathrm{~g}$, extra pure powder, Acros) in distilled water (21.504 g) under stirring $(350 \mathrm{rpm})$ at $105^{\circ} \mathrm{C}$ for $16 \mathrm{~h}$. Next, the clear silicate solution was obtained by dissolving $\mathrm{CsOH} \cdot \mathrm{H}_{2} \mathrm{O}(86.104 \mathrm{~g})$ in distilled water $(21.304 \mathrm{~g})$ and $\mathrm{HS}-40$ (12.750 g, SigmaAldrich). The aluminate solution was slowly mixed with the silicate solution to obtain a clear precursor hydrosol with a molar composition of $4 \mathrm{SiO}_{2}: 1 \mathrm{Al}_{2} \mathrm{O}_{3}: 16 \mathrm{Cs}_{2} \mathrm{O}: 164 \mathrm{H}_{2} \mathrm{O}$. The mixture was subjected to hydrothermal heating at $180{ }^{\circ} \mathrm{C}$ for $4 \mathrm{~h}$. The mother liquor after crystallization was separated via centrifugation (10000 rpm, $10 \mathrm{~min})$ and the water from filtrate was partially evaporated at $55{ }^{\circ} \mathrm{C}$ for $96 \mathrm{~h}$ to enable chemical compensation analysis. From the wet centrifuge cake (zeolite product), very small amount of solid was taken and dried in order to estimate the mass of water in the wet centrifuge cake. Then, the centrifuged solid was further purified with distilled water using centrifugation (10000 rpm, $10 \mathrm{~min}$ ) until the $\mathrm{pH}$ of the solid reached 8 . The purified solid was dried at $65{ }^{\circ} \mathrm{C}$ overnight, and the mass of Cs-ABW zeolite solid (denoted A-1) was recorded.

The separated mother liquid, which contained residual inorganic substances and water, was used for the subsequent cycles of synthesis. The chemical composition of the mother liquor and zeolite product was first analyzed (see Section 2.2) before subjecting to chemical compensation with the required amount of chemicals (Table 1). For example, $87.008 \mathrm{~g}$ of non-reacted mother liquor after analyzing with ICP-OES was added with $3.038 \mathrm{~g}$ of $\mathrm{Al}(\mathrm{OH})_{3}, 28.031 \mathrm{~g}$ of $\mathrm{CsOH} \cdot \mathrm{H}_{2} \mathrm{O}$, 
$36.803 \mathrm{~g}$ of water and $5.811 \mathrm{~g}$ of HS-40 so that a clear hydrosol with the same molar composition of $4 \mathrm{SiO}_{2}: 1 \mathrm{Al}_{2} \mathrm{O}_{3}: 16 \mathrm{Cs}_{2} \mathrm{O}: 164 \mathrm{H}_{2} \mathrm{O}$ was obtained. The crystallization, purification and compensation procedures were repeated and the solid products obtained after second and third subsequent syntheses were named as A-2 and A-3, respectively.

\subsection{Characterization}

The XRD patterns of the nanocrystalline Cs-ABW samples were collected on a BrukerAXS D8 X-ray diffractometer with $\mathrm{CuK}_{\alpha}$ radiation operating at $40 \mathrm{kV}$ and $10 \mathrm{~mA}(\lambda=1.5418 \AA$, scan speed of $0.2 \% \mathrm{~min}$, step size of $0.02^{\circ}$ ). The crystallite size was calculated by Scherrer equation (Eq. 1):

$$
\mathrm{L}=\frac{\mathrm{K} \lambda}{\mathrm{B} \cos \theta}
$$

where $\mathrm{L}$ is the average size of the crystals $(\mathrm{nm}) ; \mathrm{K}$ is the Scherrer constant, taken as $0.94 ; \lambda$ is the X-ray wavelength (1.5418 $\AA$ ); B is the full width at half maximum intensity (FWHM), after subtracting the line broadening (radians) and $\theta$ is the Bragg's angle.

The chemical composition of crystalline solids and non-reacted mother liquors was determined using an Varian Vista MPX ICP-OES inductively coupled plasma-optical emission spectrometer (ICP-OES). The samples were first mixed with HF solution to dissolve any nonsoluble silica and alumina. $\mathrm{H}_{3} \mathrm{BO}_{3}$ was then added into the prepared solution to prevent interferences of fluoride in the ICP-OES measurement. Nitrogen adsorption-desorption was performed on a Micrometrics ASAP 2010 analyzer at $-196^{\circ} \mathrm{C}$. The samples were first degassed under vacuum for $12 \mathrm{~h}$ at $300{ }^{\circ} \mathrm{C}$. The specific surface area of the samples was calculated using the BET equation. The pore size distributions and the average pore size of the zeolites were 
calculated from the adsorption branch of the experimental isotherm using the Barrett-JoynerHalenda $(\mathrm{BJH})$ model. The total pore volume of the solids was computed from the nitrogen adsorbed volume at $\mathrm{P} / \mathrm{P}_{\mathrm{o}}=0.993$. High-resolution transmission electron micrographs were recorded with a field emission TECNAI G 20 S-TWIN TEM microscope (FEI, $200 \mathrm{kV}$ ). The particle size and colloidal stability of Cs-ABW nanocrystals in water were measured using

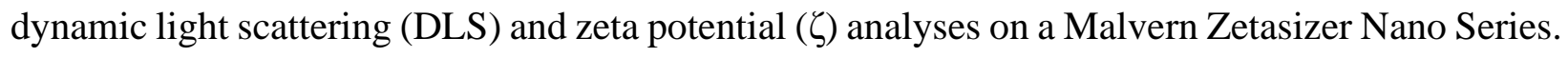
The infrared (IR) spectra of the solid was recorded with a Perkin Elmer spectrometer (System 2000) using $\mathrm{KBr}$ pellet technique.

\subsection{Catalytic experiment}

Nitroaldol condensation (Henry reaction) of benzaldehyde and nitroethane was carried out following this procedure: Activated ABW zeolite (0.500 g), benzaldehyde (2 mmol, 99\%, Merck) and nitroethane (40 mmol, 97\%, Merck) were added into a $10 \mathrm{~mL}$-quartz vial. The vial was capped and subjected to microwave heating at $180{ }^{\circ} \mathrm{C}$ using a Monowave 300 microwave reactor (Anton Paar, $850 \mathrm{~W}$ output, stirring rate $400 \mathrm{rpm}$ ). The zeolite catalyst was separated while the reaction solution was withdrawn and injected into a GC-FID chromatograph (Agilent/HP 6890 GC, HP-5 capillary column) and a GC-MS spectrometer (Perkin-Elmer Clarus 500 system) for chromatography analyses.

\section{Results and discussion}

The recyclable synthesis of nanosized Cs-ABW zeolite is carried out with an initial molar ratio of $4 \mathrm{SiO}_{2}: 1 \mathrm{Al}_{2} \mathrm{O}_{3}: 16 \mathrm{Cs}_{2} \mathrm{O}: 164 \mathrm{H}_{2} \mathrm{O}$ under hydrothermal condition at $180{ }^{\circ} \mathrm{C}$ for $4 \mathrm{~h}$. After crystallization, the solid product is recovered via high speed centrifugation; $8.758 \mathrm{~g}$ of solid 
product (A-1) with $81.85 \%$ solid yield is obtained upon drying (Table 1). The non-reacted mother liquor is collected and subjected to hydrothermal treatment using the same condition but no solid product is formed.

The solution is concentrated for analysis prior to undergo chemical compensation and subsequent synthesis cycles. The mass of concentrated waste mother liquor is $87.008 \mathrm{~g}$ and the $\mathrm{pH}$ of the solution is 14 . Hence, it indicates that there is still $\mathrm{CsOH}$ remain in the waste mother liquor. The chemical composition of the initial and waste mother liquors is characterized with ICP-OES spectroscopy and the chemicals needed for compensation are calculated and summarized in Table 1. As shown, nearly $24 \%$ of $\mathrm{CsOH}, 90 \%$ of $\mathrm{Al}$ and $45 \%$ of Si sources have been consumed during the crystallization process. As a result, the waste mother liquor does not crystallize any solid product due to insufficient $\mathrm{Al}$ and $\mathrm{Si}$ nutrients. When the calculated amount of chemicals are compensated, $6.779 \mathrm{~g}$ of solid product (A-2) equivalent to $63.36 \%$ solid yield is obtained when the second cycle synthesis is performed.

The non-reacted solution after second cycle of synthesis is separated and further subjected to partial water evaporation where $85.571 \mathrm{~g}$ of solution remains. The resulting solution has a $\mathrm{pH}$ of 14 and the elemental spectroscopy study shows that nearly $23 \%$ of $\mathrm{CsOH}, 74 \%$ of $\mathrm{Al}$ and $38 \%$ of $\mathrm{Si}$ sources are required for chemical compensation to allow the crystallization of Cs-ABW zeolite nanocrystals; $6.291 \mathrm{~g}$ of solid (A-3) or $58.79 \%$ solid yield is produced after the third cycle of hydrothermal synthesis process $\left(180^{\circ} \mathrm{C}, 4 \mathrm{~h}\right)$.

The crystalline phase of the solids (A-1, A-2 and A-3) is confirmed by XRD analysis (Fig. 1). As shown, the XRD pattern of all synthesized solids exhibits intense peaks at $2 \theta=18.80^{\circ}$, $26.94^{\circ}, 27.52^{\circ}, 32.90^{\circ}$ and $38.78^{\circ}$, which are attributed to the $(200) /(110),(211),(202) /(112)$, (310)/(020) and (312)/(022) planes of the ABW-type zeolite, respectively [34]. No extra crystalline 
phases such as ANA or tridymite are detected in the XRD patterns, indicating that only nanocrystalline Cs-ABW zeolite is formed in those three samples. The XRD peaks also show almost similar peak intensity and peak broadening indicating that the nanosized Cs-ABW zeolite produced have nearly same crystallite size with same crystallinity [37]. According to Scherrer equation, the crystallite sizes of A-1, A-2 and A-3 are 33.1, 30.8 and $29.6 \mathrm{~nm}$, respectively.

Fig. 2 shows the particle size distribution of the nanosized Cs-ABW crystals produced from the three subsequent cycles of synthesis. The A-1 nanocrystals are sized from $25.2 \mathrm{~nm}$ to $86.4 \mathrm{~nm}$ and the average crystal size is $49.4 \mathrm{~nm}$. The average crystal size decreases slightly to $46.1 \mathrm{~nm}$ and $43.4 \mathrm{~nm}$ for A-2 and A-3, respectively, but the particle size distribution remains unaffected which is in line with the XRD observation. The nanocrystals (10 wt\%) are dispersed in distilled water and the resulting colloidal solution is investigated by using zeta potential technique for colloidal stability study. The zeta potential values for A-1, A-2 and A-3 suspensions are $-52.6 \mathrm{mV},-53.7$ $\mathrm{mV}$ and $-52.7 \mathrm{mV}$, respectively, which are less than $-30 \mathrm{mV}$. Hence, it indicates good physical colloidal stability of nanosuspensions due to strong electrostatic repulsion of individual particles over attractive forces which prevents particle aggregation [38]. As a result, no sedimentation of solid is observed in the colloidal suspensions even after one month of storage under room conditions.

The morphological properties of nanocrystalline Cs-ABW zeolites prepared from the three subsequent cycles of synthesis are studied by HRTEM microscopy. As shown in Fig. 3, the nanocrystals are very homogeneous in size distribution and the average crystal sizes (A-1: 48.6 $\mathrm{nm}, \mathrm{A}-2: 44.7 \mathrm{~nm}, \mathrm{~A}-3: 42.1 \mathrm{~nm}$ ) are also nearly identical to those determined from the DLS technique (Fig. 2A). In addition, the nanocrystals exhibit orthorhombic-like shape, which is different from that of micron-sized Li-ABW crystals adapting needle-like shape (Fig. 2a-2d) [39, 
40]. The difference in morphological properties (size and shape) of nanosized Cs-ABW could be explained by the different synthesis recipe and crystallization condition by which supersaturation is achieved under very high alkalinity condition that favors nucleation over crystal growth [41]. Furthermore, low heating temperature and short crystallization time also facilitate spontaneous controlled nucleation and crystallization while lowering the crystal growth rate as compared to the previous heating temperature $\left(>700^{\circ} \mathrm{C}\right)$ and crystallization time $(46 \mathrm{~h})$.

The framework composition of nanocrystalline A-1, A-2 and A-3 solids is determined by using ICP-OES spectroscopy. The $\mathrm{Si} / \mathrm{Al}$ ratios of the samples are found to be identical and the ratios are close to unity similar to that of the theoretical value indicating homogeneous distribution of $\mathrm{Al}$ element in $\mathrm{ABW}$ framework. Furthermore, the $\mathrm{Cs} / \mathrm{Al}$ ratios of the samples are also close to unity because equivalent amount of $\mathrm{Cs}^{+}$cation is required to counter balance the negative charge of the tetrahedral $\mathrm{Al}$ species in the $\mathrm{ABW}$ framework [10].

The nitrogen adsorption-desorption isotherms of A-1, A-2 and A-3 are measured to be type $\mathrm{V}$, according to the IUPAC classification (Fig. 4) [42]. In addition, the hysteresis loops of type H1 are also obviously shown at $\mathrm{P} / \mathrm{P}_{\mathrm{o}}=0.8-1.0$, indicating that the obtained nanosized Cs-ABW samples in three subsequent syntheses are meso/macroporous materials [43]. The Barrett-JoynerHalenda (BJH) analysis also proves that these three samples have monomodal meso/macropores distribution ranging from 11 to $112 \mathrm{~nm}$ while the mean and average pore sizes of the samples decrease after subsequent cycles of synthesis. The generation of meso/macroporosities in the samples can be resulted from the textural porosities due to different stacking styles of the nanocrystals [44]. Meanwhile, very small amount of micropore surface areas $\left(<7.2 \mathrm{~m}^{2} / \mathrm{g}\right)$ are measured because nitrogen molecules $(\sigma=3.64 \AA)$ are hardly accessible to the micropores of Cs- 
ABW zeolite $\left(\sigma=3.4 \times 3.8 \AA^{2}\right)$ [45]. As a result, only meso/macropores measured as external surface area $\left(S_{\text {external }}=26-31 \mathrm{~m}^{2} / \mathrm{g}\right)$ are obtained.

Ar adsorption-desorption analysis is further used to study the porous structure of A-1, A-2 and A-3 where Ar atom $\left(\sigma=3.40 \AA, 1.64 \times 10^{-24} \mathrm{~cm}^{3}\right)$ has smaller size and lower average electric dipole polarizability than $\mathrm{N}_{2}$ molecule $\left(\sigma=3.64 \AA, 1.76 \times 10^{-24} \mathrm{~cm}^{3}\right)$ [46]. It can be seen that all samples exhibit type $\mathrm{V}$ with low Ar uptake and very narrow hysteresis loop at high $\mathrm{P} / \mathrm{P}_{\mathrm{o}}$ due to the presence of intergranular mesopores (Fig. 5). The $S_{\mathrm{BET}}$ of the samples are ca. $34 \mathrm{~m}^{2} / \mathrm{g}$, which are almost similar to those determined using $\mathrm{N}_{2}$ proble molecule. Nevertheless, the total pore volumes (ca. $0.05 \mathrm{~cm}^{3} / \mathrm{g}$ ) are much lower than those determined using $\mathrm{N}_{2}$ molecule (ca. $0.25 \mathrm{~cm}^{3} / \mathrm{g}$ ). Also, the average pore size determined using the $\mathrm{BJH}$ model is not possible because the volume adsorbed in the mesopore region is very low.

A scheme showing the total consumption of chemical reagents by both the conventional and recyclable synthesis approaches for synthesizing nanosized Cs-ABW zeolite in laboratory and industry scales is shown in Fig. 6. For laboratory scale, 3 batches of synthesis for producing $20 \mathrm{~g}$ of nanocrystalline Cs-ABW (ca. $6.67 \mathrm{~g}$ of zeolite are obtained each run) are considered using an 75-mL autoclave whereas a 100-L reactor is projected to produce 1 tonne of Cs-ABW zeolite (ca. $10 \mathrm{~kg}$ of zeolite obtained each run) via 100 industrial-scale synthesis batches. Furthermore, an assumption is also made that the amount of the raw materials used is proportional to the amount of zeolite produced as reported in Table 1 . The results show that the $\mathrm{HS}-40$ and $\mathrm{CsOH} \cdot \mathrm{H}_{2} \mathrm{O}$ consumption can be reduced up to $26.6 \%$ and $40.7 \%$, respectively, when recyclable synthesis method is applied (three cycles are used) as compared to the conventional synthesis pathway (three batches of synthesis are performed), whereas the consumption of $\mathrm{Al}(\mathrm{OH})_{3}$ is nearly similar for laboratory-scale synthesis (Fig. 6a). Hence, the production cost, which is the major concern in 
industry, can be reduced considerably. The total consumption of raw chemicals at industrial scale on the basis of 1 tonne of nanosized Cs-ABW zeolite is hence estimated for both synthesis methods (Fig. 6b). As seen, the low consumption of costly and corrosive $\mathrm{CsOH} \cdot \mathrm{H}_{2} \mathrm{O}(67.5 \%)$ and $\mathrm{HS}-40$ colloidal silica (43.8\%) is obvious, hence offering significant cost saving to industry and also environmental protection.

The catalytic behavior of A-1, A-2 and A-3 solids is also tested in Henry (nitroaldol condensation) reaction of nitroethane and benzaldehyde (as a model reaction) using microwave heating $\left(170{ }^{\circ} \mathrm{C}, 850 \mathrm{~W}\right)$ where this mode of heating provides rapid and homogeneous heating which is different from the conventional oven and oil bath heatings [47]. The results reveal that all three series of nanocrystals synthesized from the recyclable synthesis approach have consistent catalytic activity and they are very active in this Henry reaction with ca. $81.5 \%$ conversion after 10 min of microwave heating thanks to their basic sites, $(\mathrm{Si}-\mathrm{O}-\mathrm{Al})^{-} \mathrm{Cs}^{+}$, which are located at the external surface of the zeolite (Table 3: Entries 2-4). Their catalytic activity is also compared with sodium hydroxide, potassium hydroxide and sodium carbonate. Interestingly, those three nanocrystalline Cs-ABW zeolites exhibit better catalytic performance than the homogeneous catalysts (Entries 6-8). The catalytic performance of nanocrystalline Cs-ABW zeolites is also compared with those catalyzed by $\mathrm{CsOH}$ and $\mathrm{Cs}_{2} \mathrm{CO}_{3}$. The results show that Cs-ABW nanocatalysts have comparable activity as $\mathrm{Cs}_{2} \mathrm{CO}_{3}$ (82.0\%) in Henry reaction (Entry 9). Meanwhile, $\mathrm{CsOH}$, which is a very basic homogeneous catalyst, gives the highest conversion (92.4\%) after $10 \mathrm{~min}$ of reaction but it is not reusable (Entry 10). In contrast, the Cs-ABW nanocatalysts can be reused and no significant change in catalyst reactivity is observed even after the $5^{\text {th }}$ run of catalytic reaction (Entry 5), thus offering as an reusable, environment-friendly and promising solid base catalyst both in organic synthesis and chemical manufacturing. 


\section{Conclusion}

In summary, nanosized Cs-ABW zeolite can be prepared in a more cost-effective and environment-friendly way via re-using the non-reacted reagents with slight compensation of needed chemicals. The nanocrystals prepared from three subsequent synthesis batches exhibit considerably similar crystallinity, crystallite size, surface area and chemical composition whereas their morphological structure remains preserved. The nanocrystalline Cs-ABW solids prepared from this approach are also colloidally stable in water even without further surface modification. Furthermore, the recyclable synthesized Cs-ABW zeolite nanocrystals also show strong catalytic activity in base-catalyzed nitroaldol condensation of nitroethane and benzaldehyde with ca. $81.5 \%$ conversion under microwave heating. More importantly, their catalytic performance is better than that of homogenous catalysts $\left(\mathrm{NaOH}, \mathrm{KOH}, \mathrm{Na}_{2} \mathrm{CO}_{3}\right)$ and is comparable to $\mathrm{Cs}_{2} \mathrm{CO}_{3}$. Thus, the recyclable synthesis presented in this work is extremely beneficial for environment and industrial scale up process since the synthesis cost and disposal of hazardous and expensive chemical waste can be significantly reduced after the synthesis of nanocrystals, thus offering a promising option for green synthesis of aluminosilicate microporous materials.

\section{Acknowledgement}

The financial support from FRGS (203/PKIMIA/6711642) and USM Bridging (304/PKIMIA/6316506) grants is gratefully acknowledged.

\section{References}


[1] A.M. Doyle, R. Postolache, D. Shaw, R. Rothon, L. Tosheva, Methane oxidation over zeolite catalysts prepared from geothermal fluids, Micropor. Mesopor. Mater. 285 (2019) $56-60$.

[2] H. Khanmohammadi, B. Bayati, J.R. -Shahrouzi, A.-A. Babaluo, A. Ghorbani, Molecular simulation of the ion exchange behavior of $\mathrm{Cu}^{2+}, \mathrm{Cd}^{2+}$ and $\mathrm{Pb}^{2+}$ ions on different zeolites exchanged with sodium, J. Environ. Chem. Eng. 7 (2019) 103040.

[3] G. Majano, E.-P. Ng, L. Lakiss, S. Mintova, Nanosized molecular sieves utilized as an environmentally friendly alternative to antioxidants for lubricant oils. Green Chem. 13 (2011) 2435-2440.

[4] L. Tosheva, V.P. Valtchev, Nanozeolites: synthesis, crystallization mechanism, and applications, Chem. Mater. 17 (2005) 2494-2513.

[5] M. Rahimi, E.-P. Ng, K. Bakhtiari, M. Vinciguerra, H.A. Ahmad, H. Awala, S.Mintova, M. Daghighi, F.B. Rostami, M. de Vries, M.M. Motazacker, M.P.Peppelenbosch, M. Mahmoudi, F. Rezaee, Zeolite nanoparticles for selective sorption of plasma proteins, Sci. Rep. 5 (2015) 17259.

[6] S. Mintova, J. Grand, V. Valtchev, Nanosized zeolites: quo vadis?, CR Chim. 19 (2016) 183-191.

[7] S.K. Lakhera, H.Y. Hafeez, R. Venkataramana, P. Veluswamy, H. Choi, B. Neppolian, Design of a highly efficient ternary $\mathrm{AgI} / \mathrm{rGO} / \mathrm{BiVO}_{4}$ nanocomposite and its direct solar light induced photocatalytic activity, Appl. Surf. Sci. 487 (2019) 1289-1300. 
[8] C. Venkatesan, H. Park, J. Kim, S. Lee, R. Ryoo, Facile synthesis of mesoporous zeolite Y using seed gel and amphiphilic organosilane, Micropor. Mesopor. Mater. 288 (2019) 109579.

[9] R.K. Bera, H. Park, R. Ryoo, $\mathrm{Co}_{3} \mathrm{O}_{4}$ nanosheets on zeolite-templated carbon as an efficient oxygen electrocatalyst for a zinc-air battery, J. Mater. Chem. A 7 (2019) 9988-9996.

[10] T.M.A. Ghrear, S. Rigolet, T.J. Daou, S. Mintova, T.C. Ling, S.H. Tan, E.-P. Ng, Synthesis of Cs-ABW nanozeolite in organotemplate-free system, Micropor. Mesopor. Mater. 277 (2019) 78-83.

[11] L. Tosheva, E.-P. Ng, S. Mintova, M. Hölzl, T.H. Metzger, A.M. Doyle, AlPO ${ }_{4}-18$ seed layers and films by secondary growth, Chem. Mater. 20 (2008) 5721-5726.

[12] E.-P. Ng, S.S. Sekhon, S. Mintova, Discrete MnAlPO-5 nanocrystals synthesized by an ionothermal approach, Chem. Commun. (2009) 1661-1663.

[13] G. Majano, K. Raltchev, A. Vicente, S. Mintova, High-yield nanosized (Si) AlPO-41 using ethanol polarity equalization and co-templating synthesis approach, Nanoscale 7 (2015) $5787-5793$.

[14] A.G. Mohammad S, N.H. Ahmad, K. Goldyn, S. Mintova, T.C. Ling, E.-P. Ng, Nanosized Cs-pollucite zeolite synthesized under mild condition and its catalytic behaviour, Mater. Res. Exp. 6 (2018) 025026.

[15] Y. Kamimura, W. Chailittisilp, K. Itabashi, A. Shimojima, T. Okubo, Critical Factors in the Seed-Assisted Synthesis of Zeolite Beta and "Green Beta" from OSDA-Free $\mathrm{Na}^{+}-$ Aluminosilicate Gels, Chem. Asian J. 5 (2010) 2182-2191. 
[16] X. Chen, D. Xi, Q. Sun, N. Wang, Z. Dai, D. Fan, V. Valtchev, J. Yu, A top-down approach to hierarchical SAPO-34 zeolites with improved selectivity of olefin, Micropor. Mesopor. Mater. 234 (2016) 401-408.

[17] S.-F. Wong, H. Awala, A. Vincente, R. Retoux, T.C. Ling, S. Mintova, R.R. Mukti, E.-P. $\mathrm{Ng}$, Nanocrystalline KF zeolite from rice husk silica as an eco-friendly solid base catalyst for the synthesis of jasminaldehyde under microwave irradiation, Micropor. Mesopor. Mater. 249 (2017) 105-110.

[18] E.-P. Ng, H. Awala, J.-P. Ghoy, A. Vicente, T.C. Ling, Y.H. Ng, S. Mintova, F. Adam, Effects of ultrasonic irradiation on crystallization and structural properties of EMT-type zeolite nanocrystals, Mater. Chem. Phys. 159 (2015) 38-45.

[19] H. Awala, J.P. Gilson, R. Retoux, P. Boullay, J.M. Goupil, V. Valtchev, S. Mintova, Template-free nanosized faujasite-type zeolites, Nat. Mater. 14 (2015) 447-451.

[20] V.P. Valtchev, K.N. Bozhilov, Transmission electron microscopy study of the formation of FAU-type zeolite at room temperature, J. Phys. Chem. B 108 (2004) 15587-15598.

[21] J. Kecht, B. Mihailova, K. Karaghiosoff, S. Mintova, T. Bein, Nanosized gismondine grown in colloidal precursor solutions, Langmuir 20 (2004) 5271-5276.

[22] S. Mintova, N.H. Olson, V. Valtchev, T. Bein, Mechanism of zeolite A nanocrystal growth from colloids at room temperature, Science 283 (1999) 958-960.

[23] E.-P. Ng, G.K. Lim, G.-L. Khoo, K.-H. Tan, B.S. Ooi, F. Adam, T.C. Ling, K.-L. Wong, Synthesis of colloidal stable Linde Type J (LTJ) zeolite nanocrystals from rice husk silica 
and their catalytic performance in Knoevenagel reaction, Mater. Chem. Phys. 155 (2015) $30-35$.

[24] M. Tsapatsis, T. Okubo, M. Lovallo, M.E. Davis, Synthesis and structure of ultrafine zeolite KL (LTL) crystallites and their use for thin film zeolite processing, Mater. Res. Soc. Symp. Proc. 371 (1995) 21.

[25] Y. Liu, M. Sun, C.M. Lew, J. Wang, Y. Yan, MEL-type pure-silica zeolite nanocrystals prepared by an evaporation-assisted two-stage synthesis method as ultra-low- $k$ materials, Adv. Funct. Mater. 18 (2008) 1732-1738.

[26] Y.-W. Cheong, K.-L. Wong, T.C. Ling, E.-P. Ng, Rapid synthesis of nanocrystalline zeolite W with hierarchical mesoporosity as an efficient solid basic catalyst for nitroaldol Henry reaction of vanillin with nitroethane, Mater. Express 8 (2018) 463-468.

[27] K. Jiao, X. Xu, Z. Lv, J. Song, M. He, H. Gies, Synthesis of nanosized Silicalite-1 in F media, Micropor. Mesopor. Mater. 225 (2016) 98-104.

[28] Y. Ni, A. Sun, X. Wu, G. Hai, J. Hu, T. Li, G. Li, The preparation of nano-sized H [Zn, Al] ZSM-5 zeolite and its application in the aromatization of methanol, Micropor. Mesopor. Mater. 143 (2011) 435-442.

[29] T. Kurniawan, O. Muraza, K. Miyake, A.S. Hakeem, Y. Hirota, A.M. Al-Amer, N. Nishiyama, Conversion of dimethyl ether to olefins over nanosized mordenite fabricated by a combined high-energy ball milling with recrystallization, Ind. Eng. Chem. Res. 56 (2017) 4258-4266. 
[30] W. Fan, K. Morozumi, R. Kimura, T. Yokoi, T. Okubo, Synthesis of nanometer-sized sodalite without adding organic additives, Langmuir 24 (2008) 6952-6958.

[31] H. Lee, S.I. Zones, M.E. Davis, A combustion-free methodology for synthesizing zeolites and zeolite-like materials, Nature 425 (2003) 385-388.

[32] D. Xi, Q. Sun, X. Chen, N. Wang, J. Yu, The recyclable synthesis of hierarchical zeolite SAPO-34 with excellent MTO catalytic performance, Chem. Commun. 51 (2015) 1198711989.

[33] E.-P. Ng, L. Delmotte, S. Mintova, Environmentally benign synthesis of nanosized aluminophosphate enhanced by microwave heating, Green Chem. 10 (2008) 1043-1048.

[34] IZA-SC Database of Zeolite Structures. http://www.iza-structure.org/ databases/.

[35] Z. Klika, Z. Weiss, M. Mellini, M. Drabek, Water leaching of cesium from selected cesium mineral analogues, Appl. Geochem. 21 (2006) 405-418.

[36] R. Klaska, O. Jarchow, Die Kristallstruktur und die Verzwillingung von $\mathrm{RbAlSiO}_{4}$, Z. Kristallogr. 142 (1975) 225-238.

[37] H. Derakhshankhah, M.J. Hajipour, E. Barzegari, A. Lotfabadi, M. Ferdousi, A.A. Saboury, E.P. Ng, M. Raoufi, H. Awala, S. Mintova, R. Dinarvand, M. Mahmoudi, Zeolite nanoparticles inhibit $\mathrm{A} \beta$-fibrinogen interaction and formation of a consequent abnormal structural clot, ACS Appl. Mater. Inter. 8 (2016) 30768-30779.

[38] T. Maurer, B.K. -Czarnetzki, Effect of electrolyte addition on the colloidal stability of aqueous zeolite sols, Helv. Chim. Acta 84 (2001) 2550-2556. 
[39] H.G. Liu, Q. Shi, L. Liu, H. Xu, J. Li, J. Dong, Synthesis and characterization of zeolite $\mathrm{Li}-\mathrm{ABW}$ from $\mathrm{Li}_{2} \mathrm{O}-\mathrm{Al}_{2} \mathrm{O}_{3}-\mathrm{SiO}_{2}-\mathrm{H}_{2} \mathrm{O}$, Stud. Surf. Sci. Catal. 17A (2008) 185-188.

[40] K. Spektor, A. Fischer, U. Haussermann, Crystallization of $\mathrm{LiAlSiO}_{4}$ glass in hydrothermal environments at gigapascal pressures-dense hydrous aluminosilicates, Inorg. Chem. 55 (2016) 8048-8058.

[41] S.-F. Wong, K. Deekomwong, J. Wittayakun, T.C. Ling, O. Muraza, F. Adam, E.-P. Ng, Crystal growth study of KF nanozeolite and its catalytic behavior in Aldol condensation of benzaldehyde and heptanal enhanced by microwave heating, Mater. Chem. Phys. 196 (2017) 295-301.

[42] K.S.W. Sing, The use of gas adsorption for the characterization of porous solids, Colloid Surf. 38 (1989) 113-124.

[43] F. Rojas, I. Kornhauser, C. Felipe, J.M. Esparza, S. Cordero, A.Domingueza, J.L. Riccardo, Capillary condensation in heterogeneous mesoporous networks consisting of variable connectivity and pore-size correlation, Phys. Chem. Chem. Phys. 4 (2002) 2346-2355.

[44] E.-P. Ng, D.T.-L. Ng, H. Awala, K.-L. Wong, S. Mintova, Microwave synthesis of colloidal stable AlPO-5 nanocrystals with high water adsorption capacity and unique morphology, Mater. Lett. 132 (2014) 126-129.

[45] O. Solcova, L. Matejova, P. Topka, Z. Musilova, P. Schneider, Comparison of textural information from argon (87 K), J. Porous Mater. 18 (2011) 557-565.

[46] D.R. Lide, ed., CRC Handbook of Chemistryand Physics, Internet Version 2005, http://www.hbcpnetbase.com, CRC Press, BocaRaton, FL, 2005. 
[47] C.O. Kappe, My Twenty Years in Microwave Chemistry: From Kitchen Ovens to Microwaves that aren't Microwaves, Chem. Rec. 19 (2019) 15-39.

\section{Author Contribution Statement}

Tamara Mahmoud Ali Ghrear: Doing experiment

Cyril Vaulot, T. Jean Daou: Performing Ar adsorption, paper proof-reading, response to reviewer

Eng-Poh Ng, Svetlana Mintova, Tau Chuan Ling: Give idea for the entire project, writing manuscript, paper proof-reading, response to reviewer

Soon Huat Tan: Assist in catalytic reaction, writing manuscript, paper proof-reading

Boon Seng Ooi: DLS and zeta potential analysis and discussion, paper proof-reading 


\section{Figure captions}

Fig. 1. XRD patterns of (a) A-1, (b) A-2 and (c) A-3 Cs-ABW zeolite nanocrystals.

Fig. 2. (A) DLS and (B) zeta potential curves of (a) A-1, (b) A-2 and (c) A-3 Cs-ABW zeolite nanocrystals.

Fig. 3. HRTEM images of (a-c) A-1, (d-f) A-2 and (g-i) A-3 samples at high and very high magnifications. Insets show the lattice fringes of single-crystal of Cs-ABW zeolite captured at selected square areas.

Fig. 4. Nitrogen adsorption-desorption isotherms and (Inset) pore size distributions of (a) A-1, (b) A-2 and (c) A-3 Cs-ABW zeolite nanocrystals.

Fig. 5. Argon adsorption-desorption isotherms of (a) A-1, (b) A-2 and (c) A-3 Cs-ABW zeolite nanocrystals.

Fig. 6. Total consumption of chemical reagents by conventional and recyclable synthesis methods for producing (a) $20 \mathrm{~g}$ of nanosized Cs-ABW zeolite in laboratory scale using 3 batches, and (b) 1 tonne of nanosized Cs-ABW zeolite in industry scale (estimated) using 100 batches. 


\section{Figures}

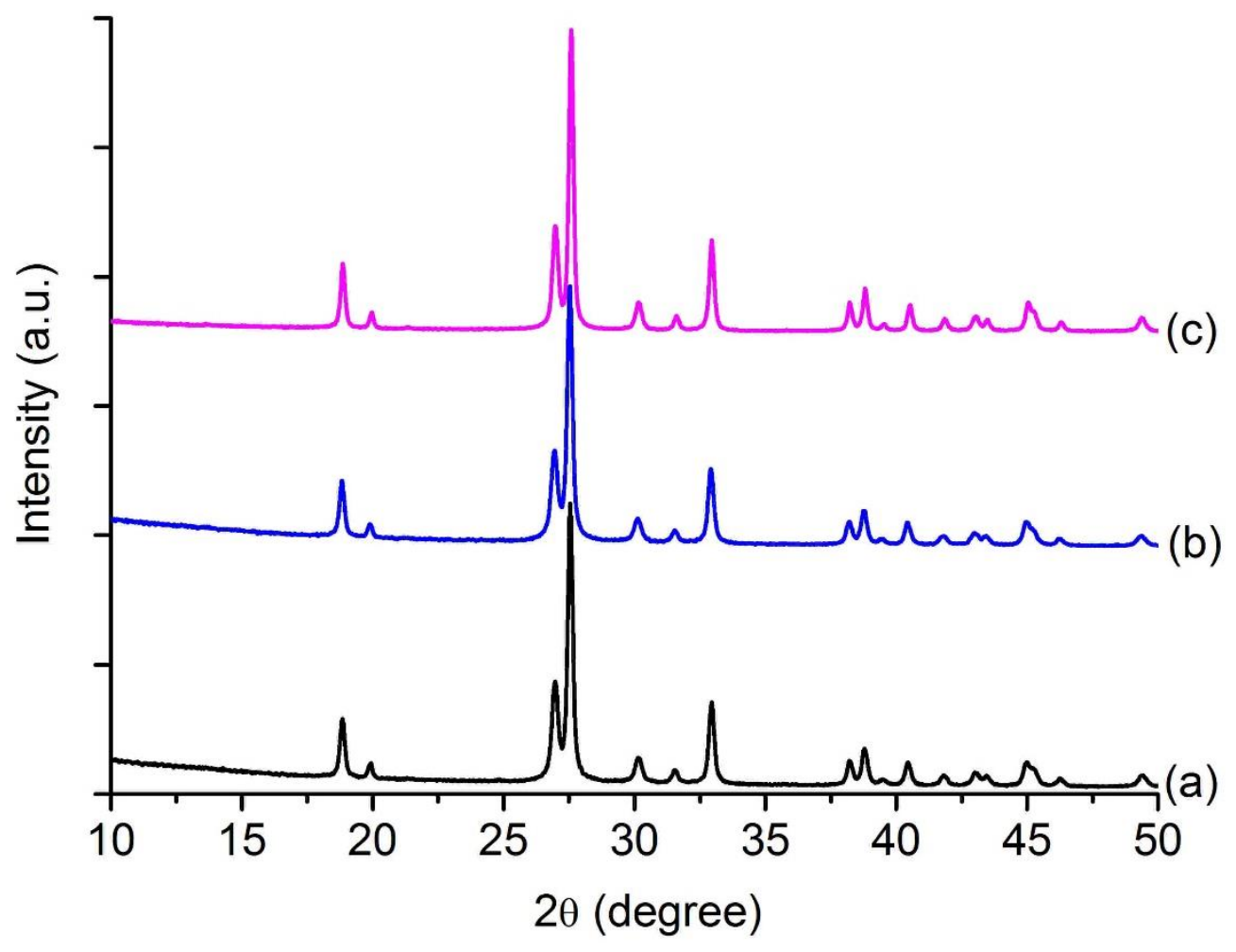

Fig. 1 


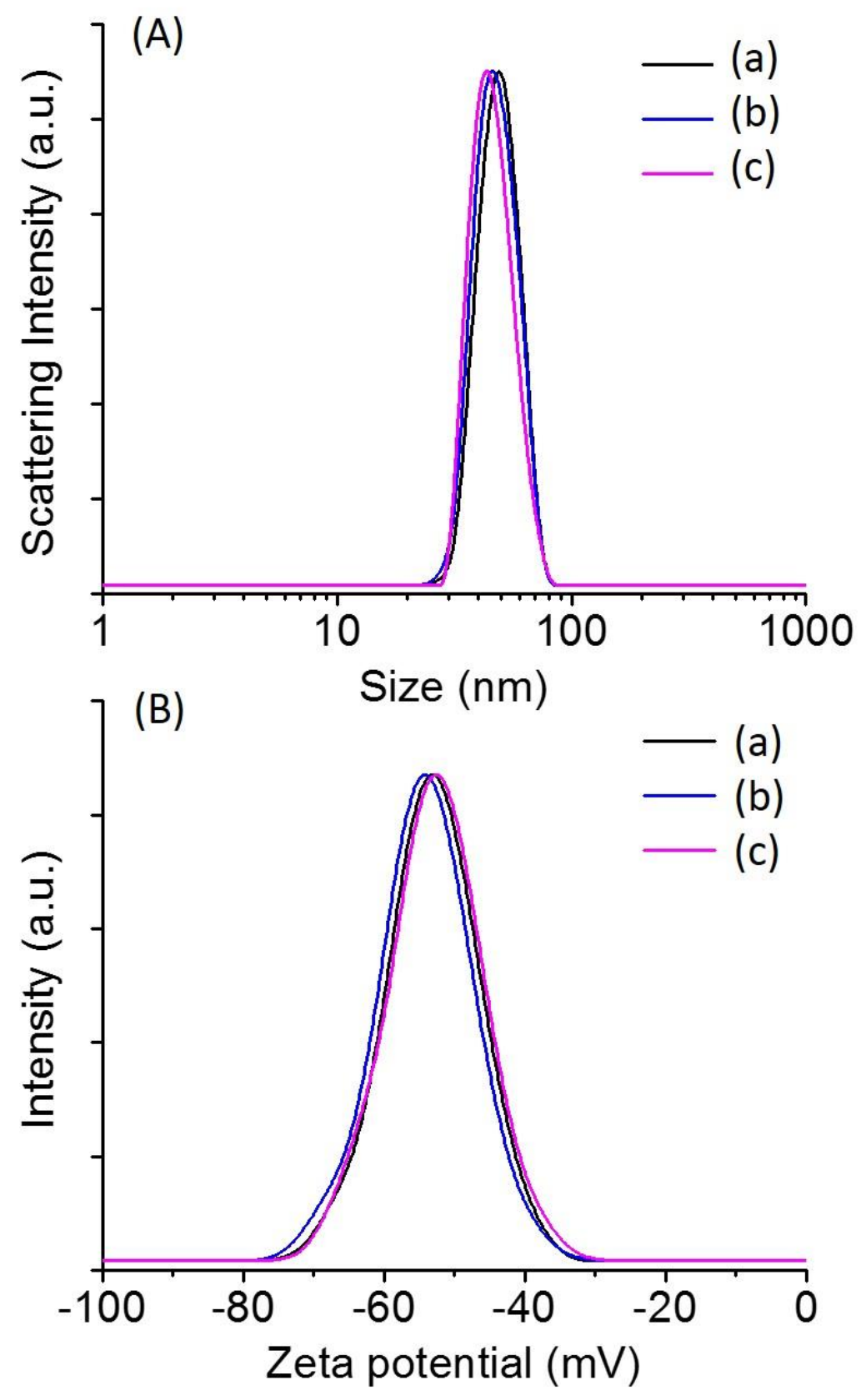

Fig. 2 


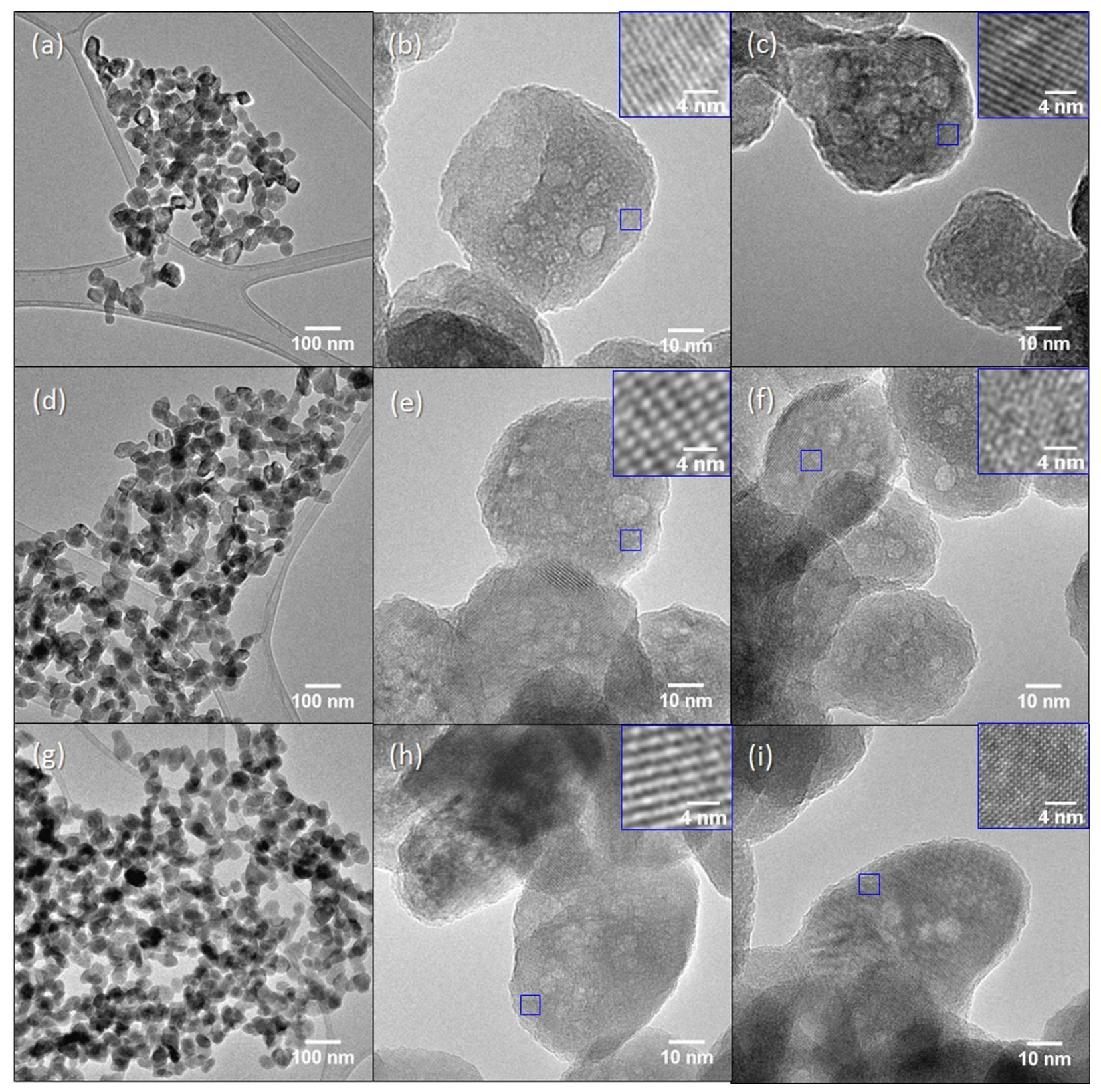

Fig. 3 


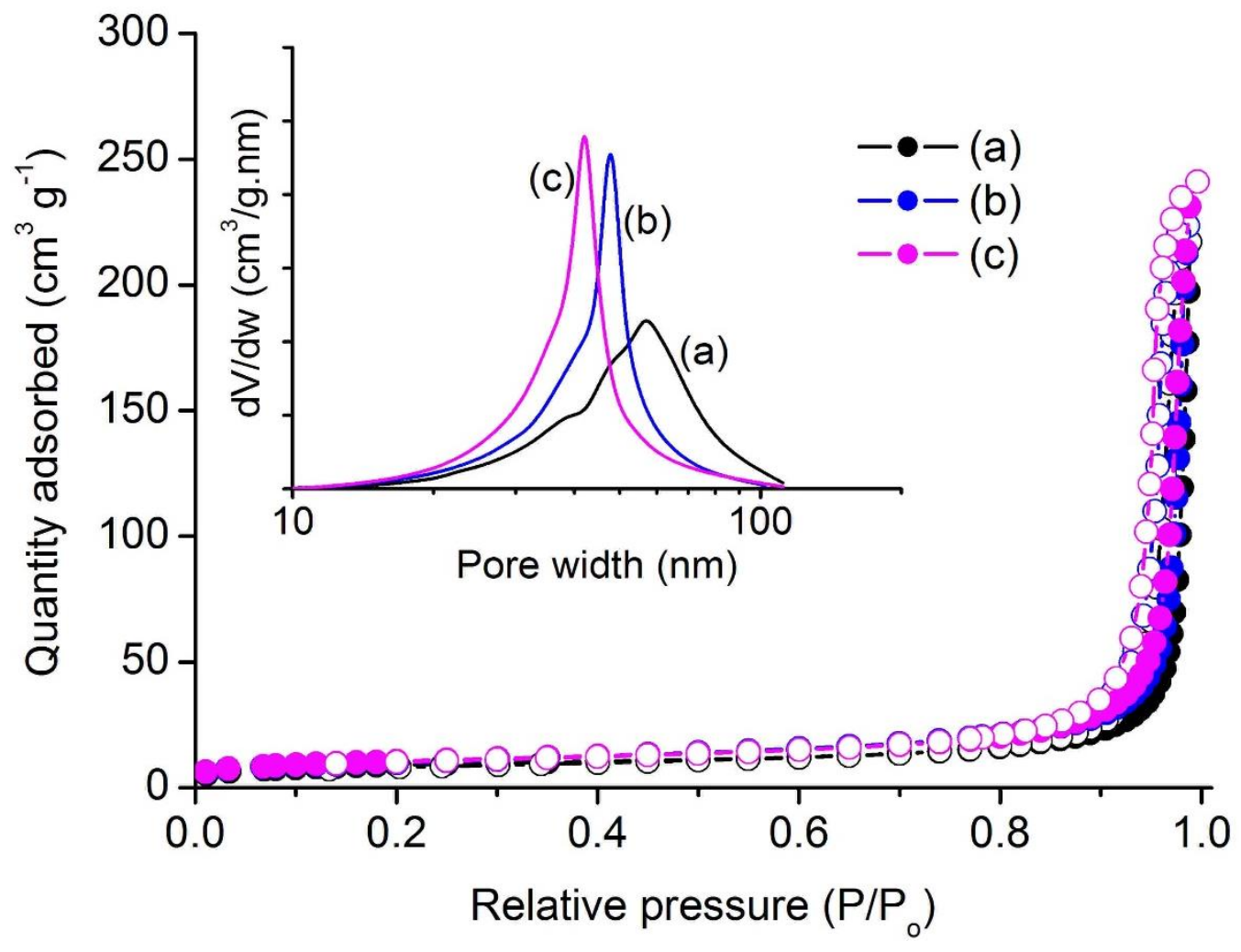

Fig. 4 


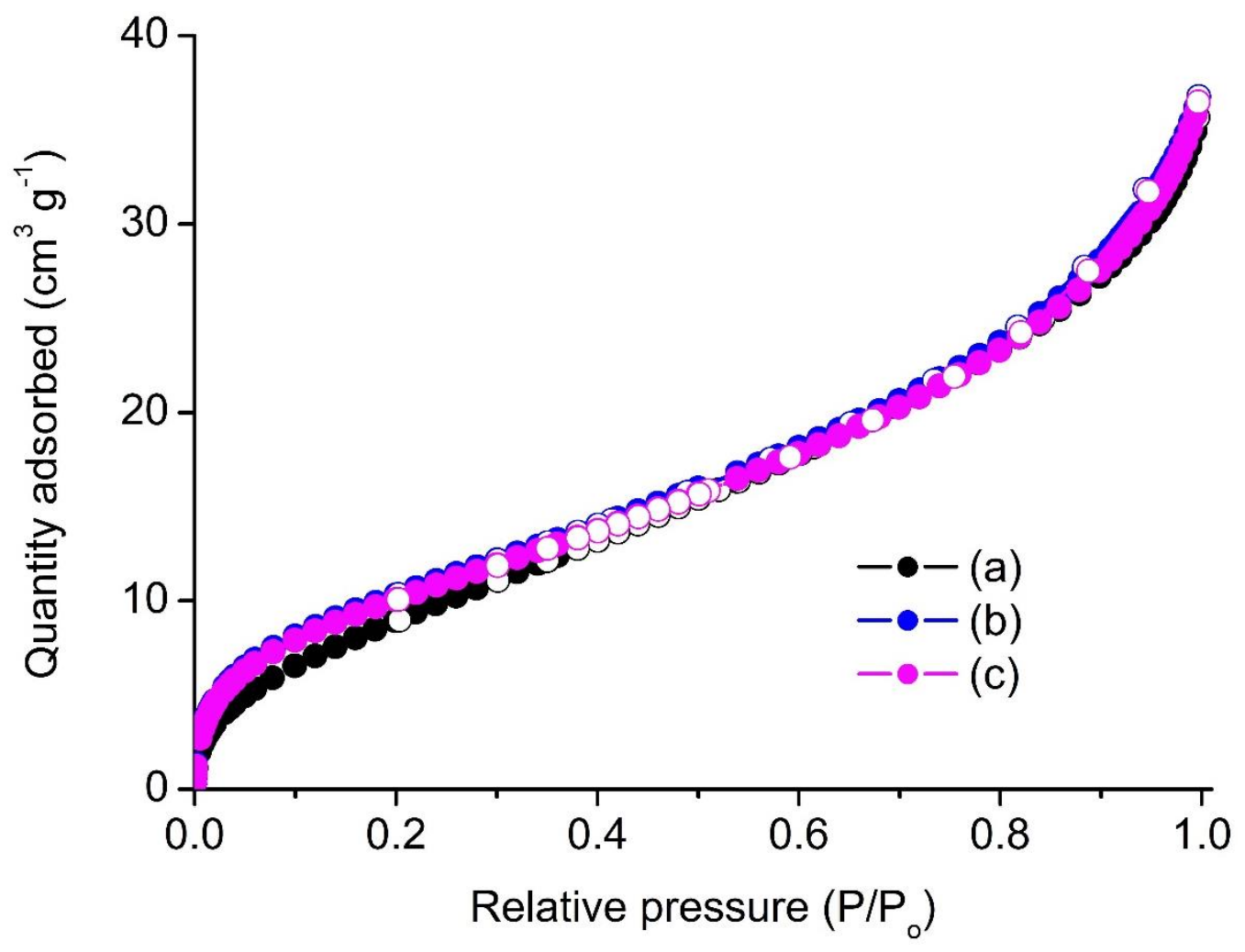

Fig. 5 

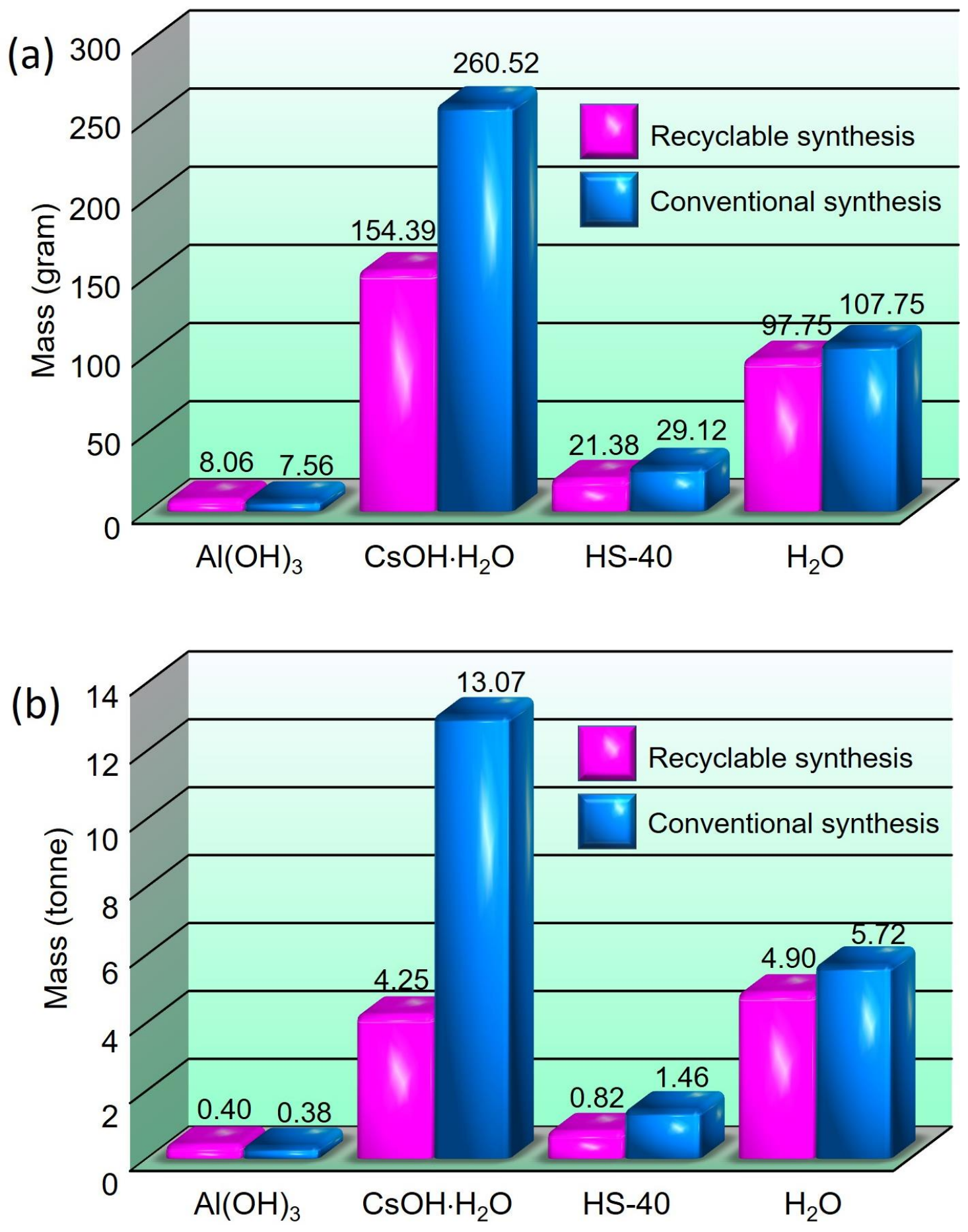

Fig. 6 


\section{$\underline{\text { Table captions }}$}

Table 1. Compensated chemicals added into non-reacted mother liquor for Cs-ABW synthesis cycles and Cs-ABW solid yield.

Table 2. Chemical compositions and textural properties of Cs-ABW zeolite nanocrystals.

Table 3. Catalytic nitroaldol condensation of benzaldehyde with nitroethane under microwave irradiation. $^{\mathrm{a}}$ 


\section{$\underline{\text { Tables }}$}

Table 1. Compensated chemicals added into non-reacted mother liquor for Cs-ABW synthesis cycles and Cs-ABW solid yield.

\begin{tabular}{|c|c|c|c|}
\hline Cs-ABW syntheis & $1^{\text {st }}$ cycle $(\mathrm{A} 1)$ & $2^{\text {nd }}$ cycle $(A 2)$ & $3^{\text {rd }}$ cycle $(\mathrm{A} 3)$ \\
\hline Non-reacted mother liquor $(\mathrm{g})$ & - & $87.008^{\mathrm{a}}$ & $85.571^{\mathrm{a}}$ \\
\hline \multicolumn{4}{|l|}{ Added chemicals } \\
\hline $\mathrm{Al}(\mathrm{OH})_{3}(\mathrm{~g})$ & 3.312 & 3.038 & 2.445 \\
\hline $\mathrm{CsOH} \cdot \mathrm{H}_{2} \mathrm{O}(\mathrm{g})$ & 114.104 & 28.031 & 26.386 \\
\hline $\mathrm{HS}-40(\mathrm{~g})$ & 12.750 & 5.811 & 4.776 \\
\hline $\mathrm{H}_{2} \mathrm{O}(\mathrm{g})$ & 42.808 & 36.803 & 37.994 \\
\hline $\mathrm{pH}$ before compensation & - & 14 & 14 \\
\hline Solid yield $(\mathrm{g}, \mathrm{wt} . \%)^{\mathrm{b}}$ & $8.758,81.85 \%$ & $6.779,63.36 \%$ & $6.291,58.79 \%$ \\
\hline \multicolumn{4}{|c|}{${ }^{\mathrm{a} A f t e r}$ evaporating water at $55^{\circ} \mathrm{C}$ for $96 \mathrm{~h}$. } \\
\hline \multicolumn{4}{|c|}{${ }^{\mathrm{b}}$ Solid yield $(\%)=\frac{\text { Weight of dried solid }(\mathrm{g})}{\text { Initial weight of } \mathrm{Al}+\mathrm{Si}+\mathrm{O}+\mathrm{Cs}(\mathrm{g})} \times 100 \%$ where $\mathrm{Al}$ is the limiting reagent and } \\
\hline \multicolumn{4}{|c|}{ the total mass in the denominator theoretically produces Cs-ABW zeolite $\left(\mathrm{Cs}_{4} \mathrm{Al}_{4} \mathrm{Si}_{4} \mathrm{O}_{16}\right)$ [34] with } \\
\hline
\end{tabular}


Table 2. Chemical compositions and textural properties of Cs-ABW zeolite nanocrystals.

\begin{tabular}{|c|c|c|c|c|c|c|c|c|c|c|c|c|c|}
\hline \multirow[t]{2}{*}{ Sample } & \multirow{2}{*}{$\begin{array}{l}\mathrm{Si} / \mathrm{Al} \\
\text { ratio }\end{array}$} & \multicolumn{2}{|c|}{$\begin{array}{c}\text { SBET } \\
\left(\mathrm{m}^{2} / \mathrm{g}\right)\end{array}$} & \multicolumn{2}{|c|}{$\begin{array}{c}\text { Smicropore } \\
\left(\mathrm{m}^{2} / \mathrm{g}\right)\end{array}$} & \multicolumn{2}{|c|}{$\begin{array}{l}\text { Sexternal } \\
\left(\mathrm{m}^{2} / \mathrm{g}\right)\end{array}$} & \multicolumn{2}{|c|}{$\begin{array}{c}V_{\text {Total }} \\
\left(\mathrm{cm}^{3} / \mathrm{g}\right)\end{array}$} & \multicolumn{2}{|c|}{$\begin{array}{l}\text { Average pore } \\
\qquad \operatorname{size}(\mathbf{n m})^{\mathrm{a}}\end{array}$} & \multirow{2}{*}{$\begin{array}{c}\text { Crystal } \\
\text { size } \\
\text { (nm) }\end{array}$} & \multirow{2}{*}{$\begin{array}{c}\text { Zeta } \\
\text { potentia } \\
\quad(\mathbf{m V})\end{array}$} \\
\hline & & $\mathrm{N}_{2}$ & $\mathrm{Ar}$ & $\mathrm{N}_{2}$ & $\mathrm{Ar}$ & $\mathrm{N}_{2}$ & $\mathrm{Ar}$ & $\mathrm{N}_{2}$ & $\mathrm{Ar}$ & $\mathrm{N}_{2}$ & $\mathrm{Ar}$ & & \\
\hline A1 & 1.03 & 31.9 & 33.4 & 5.3 & 0.2 & 26.6 & 33.2 & 0.21 & 0.04 & 46.4 & n.m. & 49.4 & -52.6 \\
\hline $\mathrm{A} 2$ & 1.02 & 36.2 & 34.7 & 4.9 & 0.1 & 31.3 & 34.6 & 0.25 & 0.05 & 39.8 & n.m. & 46.1 & -53.7 \\
\hline A3 & 1.02 & 37.3 & 34.0 & 7.2 & 0.1 & 30.1 & 33.9 & 0.33 & 0.05 & 37.1 & n.m. & 43.4 & -52.7 \\
\hline
\end{tabular}

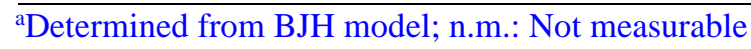


Table 3. Catalytic nitroaldol condensation of benzaldehyde with nitroethane under microwave irradiation. $^{\text {a }}$

\begin{tabular}{ccccc}
\hline & & & \\
& & & \\
& & & & \\
\hline
\end{tabular}




\section{Graphical abstract}

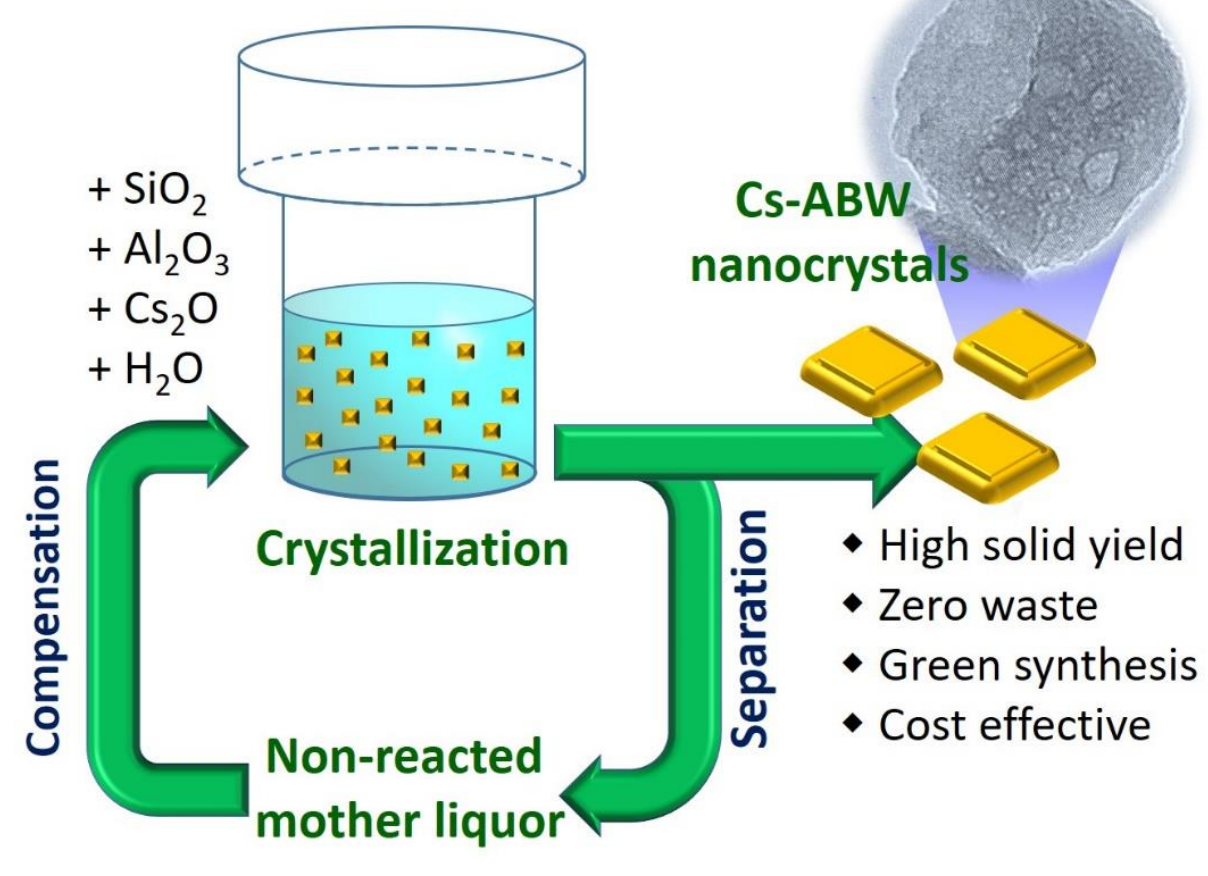

